\title{
Historical land use has long-term effects on microbial community assembly processes in forest soils
}

\author{
Ernest D. Osburn (iD ${ }^{1 凶}$, Frank O. Aylward (D) ${ }^{1}$ and J. E. Barrett ${ }^{1}$
}

(c) The Author(s) 2021

Land use change has long-term effects on the structure of soil microbial communities, but the specific community assembly processes underlying these effects have not been identified. To investigate effects of historical land use on microbial community assembly, we sampled soils from several currently forested watersheds representing different historical land management regimes (e.g., undisturbed reference, logged, converted to agriculture). We characterized bacterial and fungal communities using amplicon sequencing and used a null model approach to quantify the relative importance of selection, dispersal, and drift processes on bacterial and fungal community assembly. We found that bacterial communities were structured by both selection and neutral (i.e., dispersal and drift) processes, while fungal communities were structured primarily by neutral processes. For both bacterial and fungal communities, selection was more important in historically disturbed soils compared with adjacent undisturbed sites, while dispersal processes were more important in undisturbed soils. Variation partitioning identified the drivers of selection to be changes in vegetation communities and soil properties (i.e., soil $\mathrm{N}$ availability) that occur following forest disturbance. Overall, this study casts new light on the effects of historical land use on soil microbial communities by identifying specific environmental factors that drive changes in community assembly.

ISME Communications(2021)1:48; https://doi.org/10.1038/s43705-021-00051-x

Soil microbial communities play key roles in terrestrial ecosystems, facilitating essentially all ecosystem processes [1]. However, soil microbial communities globally are threatened by land use change, which has modified $\sim 75 \%$ of earth's ice-free land area [2] and has had wide-ranging effects on soil microbial community structure $[3,4]$ and ecosystem functions $[5,6]$. These changes in microbial communities are linked to differences in community assembly processes (i.e., selection, dispersal, drift) among land uses [7], which, in turn, are driven by specific environmental factors (e.g., soil properties) that influence soil microorganisms $[3,4]$. For example, changes in soil $\mathrm{pH}$ exert strong selective pressure on microorganisms [8] and $\mathrm{pH}$ differences among land uses influence the relative importance of different assembly processes in structuring soil microbial communities [9].

In addition to effects of present land use, currently unmanaged ecosystems with different historical management regimes may also host distinct microbial communities [10]. For example, historical forest management (e.g., logging, agriculture conversion) influences soil microbial communities for several decades after management activities have ceased and forest recovery has occurred [10]. These influences include increased bacterial diversity and increased abundance of specific microbial functional groups (e.g., nitrifiers and r-selected bacteria) in previously managed sites [10]. However, the community assembly processes and related environmental drivers that underlie these legacy effects of historical land use have not been identified. We predicted that changes in key soil properties following historical management (e.g., increased $\mathrm{pH}$ and inorganic $\mathrm{N}$ ) would serve as an environmental filter, thereby increasing the importance of homogenous selection in structuring bacterial and fungal communities in historically managed soils.

To investigate microbial community assembly across historical land uses, we sampled soils from eight forested watersheds at the Coweeta Hydrologic Lab in North Carolina, USA. Four of the watersheds were disturbed $\sim 4-8$ decades previously by management activities including clear-cutting, cable-logging, conversion to pine monoculture, and pasture conversion (Table S1). Adjacent to each historically disturbed forest is a "reference" watershed that has remained undisturbed for $\sim 100$ years (Fig. S1). Within each watershed, we established six plots, surveyed vegetation, and sampled $10 \mathrm{~cm}$ depth soils from each plot. Sampling took place in June 2018 , at the height of the growing season. We measured soil properties (Table S2) and characterized bacterial and fungal communities by amplicon sequencing of the 16S rRNA and the ITS1 regions, respectively. All sampling and sequencing methods were previously described [10]. We aligned $16 \mathrm{~S}$ sequences to SILVA [11] and aligned ITS sequences using PASTA [12], which is appropriate for regions with high sequence length variability such as ITS [13]. We then used FastTree2 [14] to construct maximumlikelihood phylogenetic trees for bacteria and fungi (Figs. S2, S3). Due to potential issues with ITS sequence alignment, we repeated all analyses using a fungal tree based on the UNITE taxonomy for our fungal OTUs, which produced nearly identical results compared with the sequence alignment approach (Figs. S4, S5).

We quantified the relative importance of different community assembly processes using the null model approach described by

${ }^{1}$ Department of Biological Sciences, Virginia Tech, Blacksburg, VA, USA. ${ }^{\bowtie}$ email: eosburn@vt.edu

Received: 23 March 2021 Revised: 1 August 2021 Accepted: 6 August 2021

Published online: 10 September 2021 

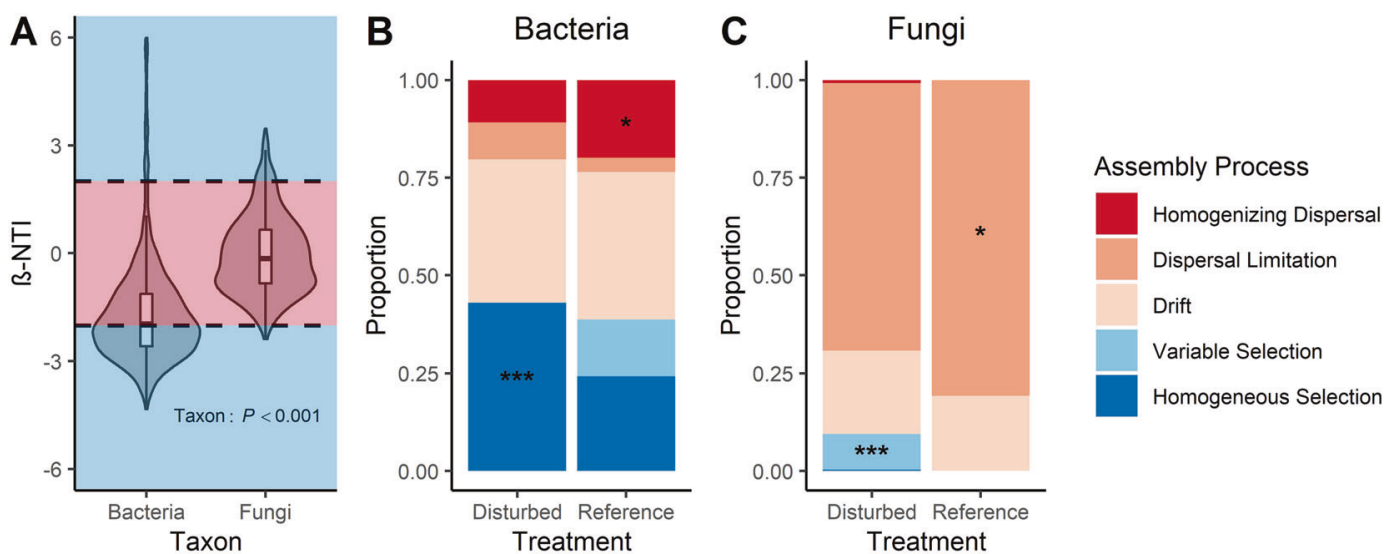

Fig. 1 Community assembly processes for bacterial and fungal communities in 'reference' and historically 'disturbed' forest soils. In (A), $\beta$ NTI distributions for bacteria and fungi are shown, while (B) and (C) show proportions of community assembly processes between historical land uses for bacteria and fungi, respectively. In all panels, shades of blue represent selection processes while shades of red represent neutral processes. In (A), phylogenetic turnover that is less than null expectations (i.e., $\beta N T I<-2$ ) indicates homogenous selection, phylogenetic turnover that is greater than null expectations (i.e., $\beta \mathrm{NTI}>2$ ) indicates variable selection, and phylogenetic turnover that does not vary from null expectations $(|\beta \mathrm{NTI}|<2)$ indicates neutral processes. In $(\mathbf{A})$ the $P$ value is from a Kruskal-Wallis test. In $(\mathbf{B})$ and $(\mathbf{C})$, asterisks represent statistically greater proportions (Z-tests) at the following significance levels: ${ }^{*} P<0.05$, ${ }^{* * *} P<0.001$. In (B), selection overall (i.e., homogeneous + variable) is greater in disturbed soil communities $(P=0.046)$.

Stegen et al [15], which assumes that closely related taxa are also ecologically similar. We confirmed this assumption for our data using the mantel correlogram method [15] (Figs. S6 and S7). The null model method distinguishes between selection and neutral processes by calculation of standardized phylogenetic turnover between communities (i.e., $\beta \mathrm{NTI})$. Phylogenetic turnover less than or greater than null expectations indicates the homogeneous or variable selection, respectively. Turnover that does not differ from null expectations indicates neutral processes. Standardized compositional turnover (i.e., $\mathrm{RC}_{\text {Bray }}$ ) then distinguishes between specific neutral processes, where compositional turnover less than or greater than null expectations indicates homogenizing dispersal or dispersal limitation + drift, respectively. Turnover not differing from null indicates drift alone. We determined differences between bacterial and fungal $\beta N T I$ distributions using a Kruskal-Wallis test and determined effects of historical disturbance on the proportions of specific processes using Z-tests. We investigated potential drivers of selection (i.e., vegetation and soil properties) by conducting variation partitioning on $\beta$ NTI matrices, similar to the approach of Fillinger et al [16]. All methodological details regarding sampling, lab methods, and statistical analyses are provided in the Supplementary Information.

For both bacteria and fungi, communities were structured primarily by neutral processes, with stochastic drift particularly important in bacterial communities (Fig. 1). However, bacteria exhibited significantly lower $\beta N T I$ than fungi (Fig. 1A), indicating greater importance of homogenous selection in structuring bacterial communities and greater importance of neutral processes in structuring fungal communities, which has also been previously reported $[13,17]$. Specifically, fungal communities were primarily structured by dispersal limitation (Fig. 1C), possibly attributed to the large proportion of dispersal-limited mycorrhizal taxa ( $30 \%$ of sequences) present in these soils (Fig. S8) [18]. The importance of homogeneous selection in structuring bacterial communities is consistent with the strong and well-known relationships between bacterial communities and specific soil properties (e.g., $\mathrm{pH}, \mathrm{N}$ availability) [3, 4]. These domain-level differences in community assembly processes likely reflect fundamental differences in bacterial and fungal life history strategies, e.g., differences in growth, dispersal, and/or dormancy methods.

Bacterial and fungal communities in historically disturbed sites were more structured by selection than reference communities
(Fig. 1B, C). Variation partitioning identified the drivers of selection to be specific vegetation and soil properties (i.e., $\mathrm{N}$ availability, Table 1). Vegetation accounted for particularly large proportions of variation in both bacterial and fungal $\beta N T I$ (Table 1), indicating that changes in vegetation and changes in soil $\mathrm{N}$ that are dependent on vegetation account for the greater selective pressures in disturbed sites. For example, the greater influence of homogeneous selection on disturbed soil bacterial communities (Fig. 1B) likely reflects consistent bacterial responses to increased $\mathrm{N}$ availability, e.g., increased abundance of $r$-selected and nitrifying taxa [4]. These increases in $\mathrm{N}$ availability, in turn, are likely linked to vegetation changes following disturbance, e.g., increased abundance of tulip poplar (L. tulipifera) and the historical dominance of $\mathrm{N}$-fixing Robinia pseudoacacia in the disturbed sites (Table 1, S1) [19]. The greater influence of variable selection on disturbed soil fungal communities (Fig. 1C) suggests the existence of distinct fungal niches in different disturbed forests due to current vegetation differences, e.g., Pinus monoculture vs. hardwood forest (Table 1, S1). Though other studies have reported the predominance of neutral processes in recently disturbed ecosystems $[17,20]$, we show that selection becomes more important later in ecosystem succession [21].

Dispersal processes were more important in structuring bacterial and fungal communities in reference soils than in disturbed soils (Fig. 1B, C). Greater homogenizing dispersal in reference soil bacteria (Fig. 1B) may be attributed to greater age and stability of the reference forests. In fungi, greater dispersal limitation in reference soils (Fig. 1C) may again reflect vegetation differences, which promote greater abundance of dispersallimited mycorrhizae in reference sites vs. disturbed sites (36 and $25 \%$ of sequences, respectively, Fig. S8) [18].

Overall, our results reveal clear legacies of historical land use on soil microbial community assembly; contrary to what has been shown for recently disturbed systems, microbial communities in historically disturbed sites can be more strongly shaped by selection than their undisturbed counterparts. However, it is possible that these patterns are specific to our soils within temperate forests of the eastern US, which should be assessed by future work. Regardless, the differences in community assembly we report are likely to influence ecosystem recovery following forest disturbance. For example, ecosystem processes associated with specific fungal taxa may recover slowly or not at all following forest disturbance, as these taxa will not be quickly recruited from 
Table 1. Partitions of variation in $\beta$ NTI accounted for by soil variables and vegetation communities.

\begin{tabular}{|c|c|c|c|c|}
\hline Taxon & Partition & Adj. $R^{2}$ & $P$ value & Significant variables \\
\hline \multirow[t]{6}{*}{ Bacteria } & Soil & 0.17 & 0.004 & Total N, Extractable N, Extractable C:N \\
\hline & Vegetation & 0.32 & 0.001 & Q. rubra, P. strobus, B. lenta, L. tuilipifera \\
\hline & Soil + Vegetation & 0.45 & 0.001 & \\
\hline & Soil | Vegetation & 0.05 & 0.003 & Total N, Extractable C:N \\
\hline & Vegetation | Soil & 0.14 & 0.001 & Q. rubra, P. strobus, B. lenta \\
\hline & Soil $\cap$ Vegetation & 0.19 & - & \\
\hline \multirow[t]{5}{*}{ Fungi } & Soil & 0.24 & 0.001 & Total N, Microbial Biomass C \\
\hline & Vegetation & 0.33 & 0.001 & R. maximum, P. strobus, L. tulipifera, Carya spp. \\
\hline & Soil + Vegetation & 0.38 & 0.001 & \\
\hline & Soil|Vegatation & 0.05 & 0.005 & Total N \\
\hline & Vegetation | Soil & 0.14 & 0.001 & R. maximum, P. strobus, L. tulipifera \\
\hline
\end{tabular}

The significance of each partition was tested using distance-based redundancy analysis (dbRDA). Note that the significance of Soil $\cap$ Vegetation cannot be tested. The significance of individual variables within each variation partition was determined using permutation tests (anova.cca function, vegan package) following dbRDA. For vegetation species, genus abbreviations are as follows: $Q$ Quercus, $P$ Pinus, $B$ Betula, $L$ Liriodendron, $R$ Rhododendron.

undisturbed sites via dispersal (Fig. 1C). In general, this study casts new light on the mechanisms that drive changes in microbial communities following forest disturbance, with implications for the key ecosystem processes that these communities facilitate.

\section{DATA AVAILABILITY}

All data and R scripts used in statistical analyses are available at the author's GitHub repository at the following URL: https://github.com/eosburn/Coweeta-Microbes/tree/ master/Community_Assembly

\section{REFERENCES}

1. Fierer N. Embracing the unknown: disentangling the complexities of the soil microbiome. Nat Rev Microbiol. 2017;15:579-90.

2. Ellis EC. Anthropogenic transformation of the terrestrial biosphere. Philos Trans $R$ Soc A-Math Phys Eng Sci. 2011;369:1010-35.

3. Jangid K, Williams MA, Franzluebbers AJ, Schmidt TM, Coleman DC, Whitman WB. Land-use history has a stronger impact on soil microbial community composition than aboveground vegetation and soil properties. Soil Biol Biochem. 2011:43:2184-93.

4. Ramirez KS, Lauber CL, Knight R, Bradford MA, Fierer N. Consistent effects of nitrogen fertilization on soil bacterial communities in contrasting systems. Ecology. 2010;91:3463-70.

5. Hermans SM, Taylor M, Grelet G, Curran-Cournane F, Buckley HL, Handley KM, et al. From pine to pasture: land use history has long-term impacts on soil bacterial community composition and functional potential. FEMS Microbiol Ecol. 2020;96:1-12.

6. Keiser AD, Knoepp JD, Bradford MA. Disturbance decouples biogeochemical cycles across forests of the Southeastern US. Ecosystems. 2016;19:50-61.

7. Goss-Souza D, Mendes LW, Borges CD, Baretta D, Tsai SM, Rodrigues J. Soil microbial community dynamics and assembly under long-term land use change. FEMS Microbiol Ecol. 2017;93:1-13.

8. Tripathi BM, Stegen JC, Kim M, Dong K, Adams JM, Lee YK. Soil pH mediates the balance between stochastic and deterministic assembly of bacteria. The ISME Journal. 2018;12:1072-83.

9. Barnett SE, Youngblut ND, Buckley DH. Soil characteristics and land-use drive bacterial community assembly patterns. FEMS Microbiol Ecol. 2020;96:1-11.

10. Osburn ED, McBride SG, Aylward FO, Badgley BD, Strahm BD, Knoepp JD, et al. Soil bacterial and fungal communities exhibit distinct long-term responses to disturbance in temperate forests. Front Microbiol. 2019;10:2872.

11. Pruesse E, Peplies J, Glöckner FO. SINA: accurate high-throughput multiple sequence alignment of ribosomal RNA genes. Bioinformatics. 2012;28:1823-9.

12. Mirarab S, Nguyen N, Guo S, Wang LS, Kim J, Warnow T, et al. PASTA: ultra-large multiple sequence alignment for nucleotide and amino-acid sequences. J Comput Biol. 2014;22:377-86.
13. Wang P, Li SP, Yang X, Zhou J, Shu W, Jiang L. Mechanisms of soil bacterial and fungal community assembly differ among and within islands. Environ Microbiol. 2020;22:1559-71.

14. Price MN, Dehal PS, Arkin AP. FastTree 2 - approximately maximum-likelihood trees for large alignments. PLoS ONE. 2010;5:e9490.

15. Stegen JC, Lin X, Fredrickson JK, Chen X, Kennedy DW, Murray CJ, et al. Quantifying community assembly processes and identifying features that impose them. ISME J. 2013;7:2069-79.

16. Fillinger L, Hug K, Griebler, C. Selection imposed by local environmental conditions drives differences in microbial community composition across geographically distinct groundwater aquifers. FEMS Microbiol. Ecol. 2019;95:1-12.

17. Powell JR, Karunaratne S, Campbell CD, Yao H, Robinson L, Singh BK. Deterministic processes vary during community assembly for ecologically dissimilar taxa. Nat Commun. 2015;6:8444.

18. Peay KG, Schubert MG, Nguyen NH, Bruns TD. Measuring ectomycorrhizal fungal dispersal: macroecological patterns driven by microscopic propagules. Mol Ecol. 2012;21:4122-36.

19. Elliott KJ, Vose JM. The contribution of the Coweeta Hydrologic Laboratory to developing an understanding of long-term (1934-2008) changes in managed and unmanaged forests. For Ecol Manag. 2011;261:900-10.

20. Zhang X, Johnston ER, Liu W, Li L, Han X. Environmental changes affect the assembly of soil bacterial community primarily by mediating stochastic processes. Global Change Biology. 2016;22:198-207.

21. Dini-Andreote F, Stegen JC, Elsas JD, van, Salles JF. Disentangling mechanisms that mediate the balance between stochastic and deterministic processes in microbial succession. Proc Natl Acad Sci USA. 2015;112:E1326-32.

\section{ACKNOWLEDGEMENTS}

This work was funded by the Coweeta LTER, funded by the National Science Foundation grant DEB-1637522. We thank the Coweeta Hydrologic Laboratory, Southern Research Station, USDA Forest Service for support, and Angela Weisel for assistance with field soil sampling and laboratory analyses. We also thank Bobbie Niederlehner for help with analytical chemistry.

\section{AUTHOR CONTRIBUTIONS}

E.D.O. and J.E.B. designed the study. E.D.O. conducted soil sampling and lab analyses. E.D.O. and F.O.A. conducted data analyses. All authors contributed to writing and editing the manuscript.

\section{COMPETING INTERESTS}

The authors declare no competing interests. 


\section{ADDITIONAL INFORMATION}

Supplementary information The online version contains supplementary material available at https://doi.org/10.1038/s43705-021-00051-x.

Correspondence and requests for materials should be addressed to Ernest D. Osburn.

Reprints and permission information is available at http://www.nature.com/ reprints

Publisher's note Springer Nature remains neutral with regard to jurisdictional claims in published maps and institutional affiliations.
Open Access This article is licensed under a Creative Commons Attribution 4.0 International License, which permits use, sharing, adaptation, distribution and reproduction in any medium or format, as long as you give appropriate credit to the original author(s) and the source, provide a link to the Creative Commons license, and indicate if changes were made. The images or other third party material in this article are included in the article's Creative Commons license, unless indicated otherwise in a credit line to the material. If material is not included in the article's Creative Commons license and your intended use is not permitted by statutory regulation or exceeds the permitted use, you will need to obtain permission directly from the copyright holder. To view a copy of this license, visit http://creativecommons. org/licenses/by/4.0/.

(c) The Author(s) 2021 